\title{
Author Correction: Customer support ticket escalation prediction using feature engineering
}

\author{
Lloyd Montgomery ${ }^{1}$ [ $\cdot$ Daniela Damian ${ }^{1} \cdot$ Tyson Bulmer $^{1} \cdot$ Shaikh Quader $^{2}$
}

Published online: 23 May 2018

๑) Springer-Verlag London Ltd., part of Springer Nature 2018

\section{Correction to: Requirements Engineering https://doi.org/10.1007/s00766-018-0292-3}

The original version of this article contains an error in the Acknowledgements section. The correct text should read as follows:

Acknowledgements We thank IBM for their data, advice, and time spent as a collaborator: Keith Mackenzie at IBM Victoria for his time and access to his team, Jean-Francois Puget for his guidance towards using XGBoost, and Chad Marston and Tracy Bolot for management and funding support. We thank Emma Reading for her contribution to the prototype tool. We thank the anonymous referees of both RE17 and the REJ special issue. This research was funded by the Natural Sciences and Engineering Research Council of Canada (NSERC) and IBM Center for Advanced Studies (IBM CAS).

The original article can be found online at https://doi.org/10.1007/ s00766-018-0292-3.

Lloyd Montgomery

lloydrm@uvic.ca

Daniela Damian

danielad@uvic.ca

Tyson Bulmer

tysonbul@uvic.ca

Shaikh Quader

shaikhq@ca.ibm.com

1 University of Victoria, Victoria, Canada

2 Private Cloud Platform Digital Support, IBM, Toronto, Canada 